\title{
Kuidas Anu Korb Siberisse jõudis
}

\author{
Küsimusi Anule tema 60. sünnipäeval
}

Ave Tupits

\section{Räägi palun alustuseks veidi oma lapsepõlvest. Sündinud oled Sa Kärdlas?}

Hiiumaa ja täpsemalt Kärdlaga ei seo mind küll kahjuks muu kui fakt, et olen tõepoolest saarel sündinud. Nimelt suunati minu Pärnumaalt pärit ema ja Läänemaa juurtega isa pärast põllumajandustehnikumi lõpetamist Hiiumaale tööle. Olin vaid aastane, kui isa sealt omakorda Saaremaale suunati. Ta lõpetas põllumajandusülikooli agronoomia erialal ning töötas tolleaegses MTJs, hiljem rajooni põllumajandusvalitsuses. Ema oli aastaid rajoonilehe toimetuses. Niisiis oleme juhuse tahtel õega, tema on minust kaks aastat vanem, Hiiumaal sündinud, vennad on nooremad ning sündisid juba suuremal saarel.

Saaremaal elasime Kuressaares (siis kandis linn Kingissepa nime), seal kodunesin päris hästi. Tol ajal organiseeriti vanemate töökohtadest aeg-ajalt peredega väljasõite loodusesse. Sõideti tavaliselt veoauto kastis, istmeks lihtsad puupingid. Neil teekondadel lauldi alati, üks populaarsematest oli "Hoia kinni, muidu võid sa uppi lennata..."

Sugulasi meil saarel ei olnud, kuid suvekuudel käis meil palju külalisi. Saaremaa oli ju piiritsoon, kuhu pääses vaid küllakutsega. Neid kutseid saatsid minu vanemad sugulastele-tuttavatele järjepidevalt.

Vanavanemad elasid mandril, sõitsime aeg-ajalt nendele külla. Lapsepõlvest on emakodust meelde jäänud lõbusad laulu ja tantsuga perepeod, isa vanemad olid pigem kinnised ja omaette-hoidjad. Ometi veetsin suved sageli Läänemaal isapoolsete vanavanemate juures. Seal elati traditsioonilist maaelu: peeti lehma, siga, kanu, oli kartuli- ja juurviljamaa, ounaaed, vanaisa pidas mesilasi. Vanaema hoole all olid tol ajal paarkümmend kolhoosi vasikat, kes elasid sealsamas vanavanemate õue peal laudas. Käisime perega sageli isakodus hooajatöödel abiks. Ka lehmalüpsmise sain lapsena selgeks ning seda oskust on mul folkloristina välitööl mõnigi kord vaja läinud. 


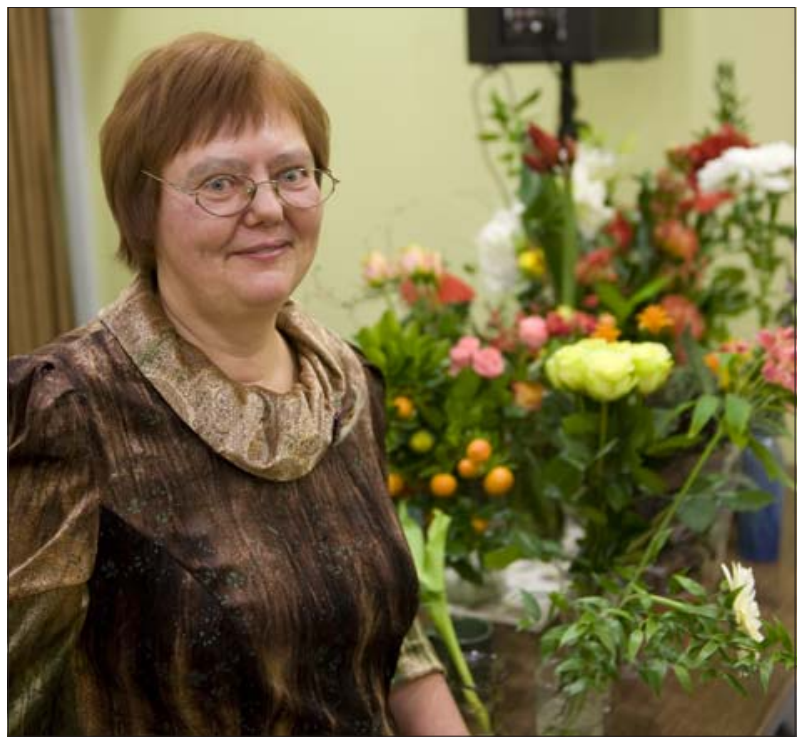

Anu Korb sidus juubeli tööga, esitledes raamatut Siberi eestlaste elud ja lood. Alar Madissoni foto 2010.

Oma esimese passi sain Saaremaal, kuid pärast minu 9. klassi lõpetamist kolis meie pere mandrile - isa sai töökoha Saue Näidissovhoosis, ema ajakirja Sotsialistlik Põllumajandus toimetuses. Üleminek kodusest Saaremaa koolist prestiižikasse Tallinna 10. Keskkooli (Nõmme Gümnaasium) ei läinud mul just kergelt: üks põhjus oli koolide tasemevahe, aga ka pealinna õpilased olid täiesti teistsugused. Kooliga harjusin pikapeale enam-vähem, aga Tallinn jäigi mulle võõraks.

\section{Kuidas sattusid Tartusse õppima?}

Edasi õppida tahtsin kindlasti Tartus, kuhu siirdusin kohe pärast keskkooli lõpetamist 1969. aasta sügisel. Kõhklesin Tartu ülikooli eesti filoloogia ja sellest täiesti erineva põllumajandusülikooli agronoomia eriala vahel. Kuna olin keskkoolis keemiaga üksjagu hädas, jäi peale eesti filoloogia.

\section{Mis sind rahvaluule juures ennekõike võlus?}

Esimese kursuse lõpul oli ette nähtud arhiivipraktika Eesti Kirjandusmuuseumis. Mõnel meist avanes selle asemel võimalus tolleaegse õppejõu ja setu kultuuri hea tundja Udo Kolgiga Setumaale rahvaluulet koguma minna. Kuigi ma seda maailma üldse ei tundnud, arvati mind ekspeditsiooni koosseisu. Siin- 
samas Eestimaal täiesti erineva kultuuri kogemus oli tõepoolest vapustav. Mäletan, et olime teisel välitööpäeval pikalt Perdaku küla laulunaisi kuulanud ja salvestanud ning sellele järgnenud ööl ei saanud ma kuidagi sõba silmale - seto helü oli ikka kõrvus. Vähkresin peaaegu hommikuni välja. Selgus, et nii mõnigi ekspeditsioonikaaslane oli samamoodi kimpus.

Järgmisel suvel olin ettenähtud keelepraktika asemel taas Udo Kolgiga Setumaa välitööl. Imestan, et meiesuguseid algajaid sinna taas kaasa võeti, aga küllap oli sel oma pedagoogiline eesmärk. Tookord oli kasu vähemalt mu lehmalüpsmisoskusest, sest meie perenaine läks päevaks kaugele heinamaale ja jättis lõunase lüpsi meie hooleks.

Kitsam erialale spetsialiseerumine toimus tol ajal pärast kolmandat kursust ning selleks ajaks olin kindlalt otsustanud rahvaluule kasuks. Kolmanda välitöö-praktika tegin pärast neljandat kursust Lihula kandis.

\section{Kuidas sattusid tööle kirjandusmuuseumi?}

Olin 1972. aasta kevadel abiellunud ja lapsed sündisid üsna järjest. Tol ajal polnud tudengipõlves lapse saamine veel tavaline. Sõbrannad konspekteerisid mulle läbi kopeeri loengute materjale ja ma üritasin kuidagi toime tulla. Igatahes lõpetasin ülikooli nominaalajaga 1974. aasta kevadel. Tol ajal suunati noored spetsialistid tööle ning põhiosa meist saadeti õpetajateks. Mina sain tänu abieluseisusele töökoha Tartu 2. Keskkoolis (nüüd Miina Härma Gümnaasium). Üsna pea sai mulle selgeks, et õpetajaamet pole minu jaoks. Töötasin koolis vaid mõned kuud ja siis sündis kolmas laps. Õpetaja kohta Tartusse ihaldasid paljud ja nii sain koolist tulema enne ettenähtud kolme kohustuslikku aastat.

1975. aasta 1. novembrist sain teadustöötaja koha kirjandusmuuseumi rahvaluule osakonda. Mind võttis tööle Ellen Liiv, arhiivi juhataja oli siis Olli Kõiva. Uus koosseisuline koht oli ette nähtud monumentaalsete regilauluväljaannete ettevalmistamiseks. Minu ülesandeks sai regivärsiliste laulude süstematiseerimine: esmalt kihelkondade ja kogude järgi, seejärel ka tüpoloogiliselt. Algul sain väikeste laste kõrvalt töötada kolm päeva nädalas.

Tolleaegse rahvaluule osakonna välitöödel osalesin esmakordselt 1977. aasta suvel. Seal sain teistkordselt tõelise ahhaa-elamuse osaliseks. Sattusime töökaaslase Imbi Rettauga Võrumaa metsade keskel elava 82aastase Ella Hummali poole, kes esitas meile hulga riimilisi rahvalaule ning hakkas lõpuks laulma vana regivärsilist vaeslapselaulu (laulutüüp "Lind lohutamas"). Sain aru, et kuulen just nüüdsama midagi väga unikaalset, laulu sõnad läksid kuidagi kõrvust mööda, mäletan vaid seda lumma, mis haaras täiega kaasa. Hiljem sel- 
gus, et nii terviklikku helivarianti meie arhiivis sellest laulust varem ei olnudki.

1979. aastal sündis poeg Kalev. Tol ajal anti lapsehoolduspuhkust aasta. Nelja lapse kõrvalt (kolisime 1980. aastal maale elama, kohapeal lasteaeda polnud) oli võimatu tööl käia. Nii olin üle kolme aasta lastega kodus, pidev tööstaaž, mis oli tol ajal oluline, katkes. Pere ülalpidamiseks hakkasin kasvatama köögivilja- ja lilletaimi ning lilleseemneid. Seesugune ettevõtlus polnud nõukogude aastatel soositud ja äratas nii mõneski kadedust. Kirjandusmuuseumi tulin taas tööle 1982. aasta sügisest.

\section{Olid 1990. aastatel Eesti Rahvaluule Arhiivi juhataja - millisena seda kogemust mäletad? See oli ju Eesti teadus- ja kultuuriasutustele täiesti uus situatsioon ja aeg.}

Tol ajal polnud meie töökohad erinevalt praegusest valitavad. Arhiivi koosseisus oli umbes kümme inimest. Pärast Ellen Liivi pensionileminekut sai juhatajaks Urmas Oras, seejärel Janika Oras. Kui Janika lapsehoolduspuhkusele jäi, sain esialgu arhiivijuhataja kohusetäitjaks. See oli muidugi hädapärane variant. Võtsin ameti vastu raske südamega ja lootsin, et Janika tööle naasmine mu sellest hiljem vabastab. Paraku nii ei läinud. Tagantjärele pean ütlema, et see amet ei olnud minu jaoks. Arhiivijuhataja töö vajab laiemat nägemust tervikust, märksa aktiivsemat suhtlemist välismaailmaga. Samas toimus uurimisvaldkondade avardumine ning tohutu tehniline areng: kultuuri- ja teadusfondide abil saadi esimesed arvutid, digitaalne helitehnika jm, elu muutus suuresti projektipõhiseks. Tublide kolleegide toel arhiiv siiski toimis. Tore, et meie paremate kogujate meelespidamiseks sai taastatud Eesti Vabariigi Presidendi rahvaluule kogumispreemia.

\section{Sa oled juba mitukümmend aastat kogunud Venemaal elavate eestlas- te pärimust ning sellel teemal palju artikleid ja ettekandeid teinud. Mis Sind Siberisse viis?}

Isegi ei oska täpselt öelda, mis mind esmalt Siberi poole tõmbas, ehk eeskätt uudishimu. Esimene kokkupuude Siberi eestlastega, see oli 1991. aasta augustis Krasnojarski krai Ülem-Suetuki külas, sai määravaks. Juba see, et Eestimaast ligikaudu $5000 \mathrm{~km}$ kaugusel külatäie inimestega (umbes 300) vabalt emakeeles suhelda saab, oli täiesti üllatav. Olin selleks ajaks teinud üksjagu välitöid Eestimaa eri paigus, selles Siberi külas aga elasid vanad traditsioonid ehedal kujul edasi: raviloitse kasutati aktiivselt igapäevaelus, esivane- 
mate kommetest peeti kinni, lauldi peast pikki eestikeelseid laule, kuigi viisid olid tuntavalt venemõjulised, räägiti vanu usundilisi jm jutte.

Tundsin, et ees on mõõtmatu tööpõld. Sestpeale hakkasin sihipäraselt tegutsema: tutvusin varemkogutud materjalidega, püüdsin võimalikult kõik püsinud Siberi eesti kogukonnad üles leida ning neis heli- ja videomaterjali jäädvustada. Selgus, et umbes 1/3 Siberi eesti kogukondadest polnud ükski Eesti uurija töötanud. Arhiivi tehniline baas oli 1991. aastatel suhteliselt nõrk, niisiis on salvestatud materjali hulk aasta-aastalt kasvanud. Õnneks loodi Eesti Rahvuskultuuri Fond, alates 1992. aastast saime sealtkaudu mitu aastat 2-4liikmelisele välitöörühmale sõiduraha. Hiljem saime abi ka Kultuurkapitalilt, Avatud Eesti Fondilt, Eesti Teadusfondilt jm.

\section{Selle pika aja jooksul on Sulle endale ilmselt hulganisti kogunenud toredaid seiku ja mälestusi, meenuta neist mõnda.}

Südamlikke kohtumisi uuritavatega on olnud niivõrd palju, et üht konkreetset on päris raske välja tuua. Näiteks 1997. aastal sõitsime neljaliikmelise rühmaga (minuga koos olid tookord Aivar Jürgenson, Astrid Tuisk ja Ell Vahtramäe) Siberisse kohe 1. jaanuari õhtul. Kui lõpuks Omski oblasti Tsvetnopolje külla jõudsime ja Linda Tsirgu uksele koputasime, tuli naine vastu rõõmsa

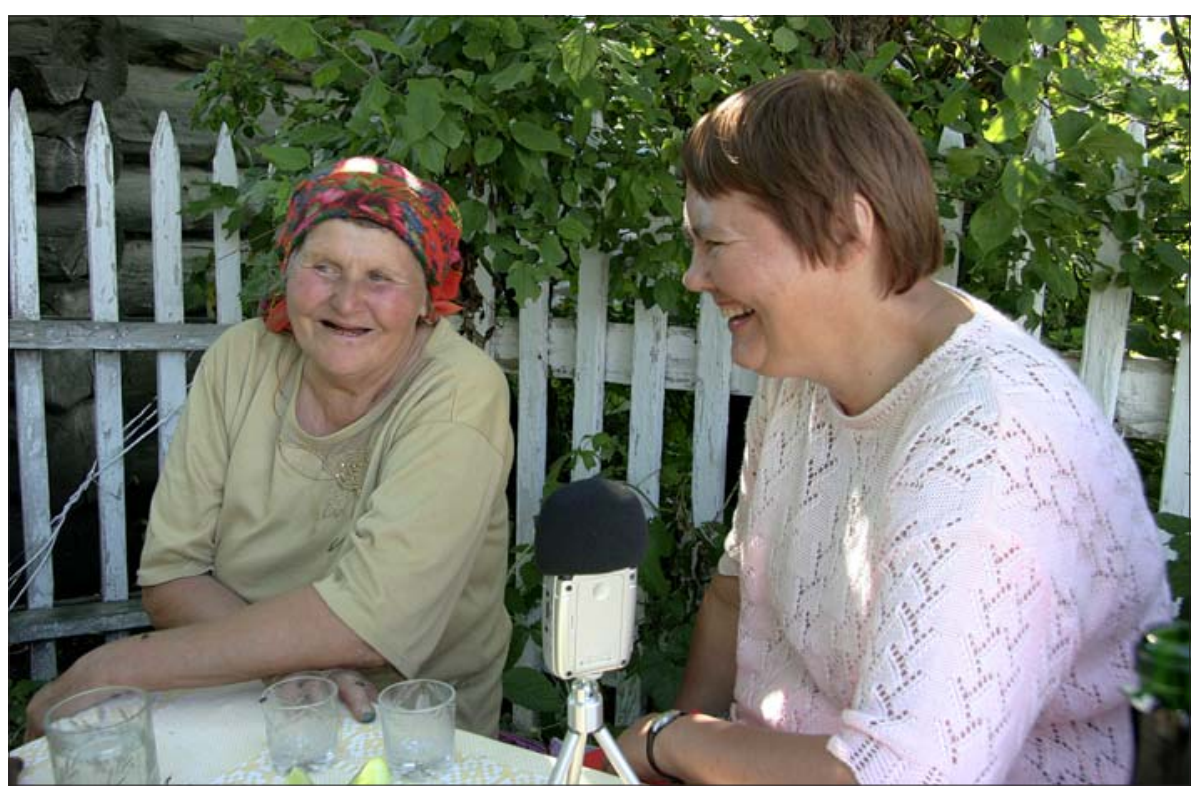

Anu Korb Petersoni Mannit küsitlemas. Haida küla Krasnojarski krais. Astrid Tuisu foto 2008. 
hüüatusega: "Või Eestimaalt! Lõpuks ometi!" Nagu oleks meid pikisilmi iga päev oodatud. Meie muide polnud oma tulekust eelnevalt teada andnud, kuid aasta-paar varem oli seal töötanud rahvastikugeograaf Hill Kulu.

1998. aastal, kui töötasime Novosibirski oblasti Orava külas, anti mulle kaasa külas filmitud koduvideo, et ma selle nende Tartus elavatele sugulaste viiksin. Kui Tartus antud aadressil kohale läksin, imestati siiralt: "Või teie olite meie Orava külas! Me arvasime, et siin Eestis keegi ei teagi meie küla!"

\section{Kas oled oma informantidelt saanud tagasisidet oma teadlasetööle?}

Pikaaegse arhiivitöö kogemusega uurijana pean materjali kogumist-korraldamist-uurimist ja populariseerimist ühe protsessi osaks ning võrdselt oluliseks. Palju südamlikke kohtumisi on olnud vestlusõhtutel, kuhu mind on Siberi eestlastest rääkima kutsutud. Südantsoojendav oli ka tänavu märtsikuus näituse "Siberi eestlased" (koostasime selle koos Kadri Viiresega) avamine Krasnojarski krai Teadusraamatukogus. Krasnojarski Eesti Selts sai tänu näitusele kindlasti rohkem tähelepanu. Meie ettevõtmist tunnustasid ka need, kel pole Eestiga mingit seost.

Ajapikku olen saanud mitmete uuritavatega lähemalt tuttavaks ning seetõttu ka päris palju tagasisidet. Antoloogia Siberi eestlased plaatide kuulamine paneb neist küladest pärit eestlasi heldima: see olevat nagu taaskohtumine Siberi kodu ja vanade aegadega.

Sarja "Eesti asundused" ilmumise järel on mind korduvalt südamlikult tänatud, et olen niisugused raamatud kokku pannud, kust võib lugeda omaenda jutte, kombeid jm. Veel tänavu septembris sain tundmatult noormehelt e-kirja, kes kirjutas:

Mind ajendas Teile seda väikest meili saatama selline sündmus, et sattusin 7-liikmelise automatkajate grupi koosseisus Tomski kandis Siberi külakesse Vambolõ, kus Teie raamat Seitse küla Siberis suure au sees oli. [---] Vennad Langmetsad helistasid ka oma isale, ta oli raamatus ka ühel pildil lõõtsa mängimas. Tegu oli väga elurõõmsa taadiga, kes eelpool mainitud raamatu (üsna kapsaks juba loetud) kaasa haaras ja portveiniga kohale kihutas.

Samas olen nendesamade väljaannete kohta kuulnud ka kriitikat: mõned noorelt külast lahkunud inimesed arvasid, et nende sünnikülas pole ebausukombeid ja loitse kunagi olnudki või on see hiljem venelastelt õpitud ning niisugust lora pole mõtet trükis avaldada.

Ehk kõige ehedama elamuse pakkus kirjandusmuuseumi saalis 2003. aasta sügisel esmakordselt korraldatud kogupere-üritus "Venemaale veerenud". 
See oli suunatud eeskätt Eestis elavatele Siberis sündinud eestlastele, et neile Siberi eesti küladest kogutud materjali tutvustada. Kokkutulnuid oli nii palju, et muuseumi saal sai puupüsti rahvast täis. Kui suurel ekraanil Siberi eesti külades tehtud fotosid näitasime, elati saalis nii elavalt kaasa, et ainuüksi see emotsioon vääris ürituse korraldamist.

\section{Oled teinud pikalt sarja "Eesti asundused". Kuidas sündis Sinu vii- mane kogumik Siberi eestlaste elud ja lood, mida võib sealt leida?}

Sarja "Eesti asundused" (ilmunud 1995-1999) neli raamatut on folkloorikesksed, pakkudes ülevaadet konkreetse piirkonna pärimusmaterjalist. Iga Siberi eestlaste küla tahaks muidugi omaküla raamatut, kuid ilmselt pole kuigi mõistlik teha näiteks kümmet piirkondlikku väljaannet. Otsustasin, et niisugusel kujul enam sarja ei jätka.

Loodetavasti laiemat huvi pakkuvat Siberi eestlaste mälestuste raamatut, mis keskendub küla- ja elulugudele, olin üsna mitu aastat meeles kandnud ning alustanudki, kuid ikka oli see muude pakiliste tegemiste kõrval tahaplaanile jäänud. Nüüd otsustasin, et pean selle lõpuks valmis saama. Esmalt ei plaaninud ma seda "Eesti asunduste" sarja raamatuna. Pikema kaalumise järel leidsin, et miks ka mitte. Raamatus leiduvad lood on eestlastelt, kelle esivanemad olid Siberisse välja rännanud või sattunud sinna muul moel. Nad kõik sündisid Siberis ning jõudsid Teise maailmasõja ajal või hiljem oma esivanemate kodumaale. Lugusid olen parema loetavuse huvides sedakorda märksa enam toimetanud kui varasemate raamatute puhul. Raamatusarja uut kvaliteeti rõhutavad ka senisest erinev formaat ja kõvad kaaned.

\section{Millised on Sinu lähiaja tööplaanid?}

Viimased aastad on olnud liigagi töised ning raske on leida tasakaalu töö ja puhkuse vahel. Koostöös Andreas Kalkuniga on praegu käsil CD/DVD antoloogia Siberi setode laulud koostamine. Ehk õnnestub see 2011. aastal välja anda. Lähiaastatel on kavas ilmutada ka mujal Venemaa asundustes (v.a Siber) sündinud-kasvanud eestlaste elu- ja külalood. Järge ootab tekstikriitiline väljaanne ERA omaaegse Siberi korrespondendi Rosalie Ottessoni saadetistest. Lähemalt tahaksin uurida veel Vologda-Vjatka ja Simbirski piirkonna eestlaste pärimust, mille kohta olen üksjagu materjali kogunud. Kogutu uurimisvõimalused on ju peaaegu ammendamatud ning alati võib kaevuda sügavamale. Põnev oleks tegeleda ka millegi muuga, näiteks nüüdisfolklooriga, aga neid plaane vist ei tasu enam tõsiselt võtta. 


\section{Summary}

\section{Interview with Anu Korb on her 60th birthday}

Anu Korb, folklorist and frequent visitor to Siberian Estonians, who celebrated her 60th birthday on 27 November, is interviewed by Ave Tupits 